\title{
Research on New Knowledge Introduction of Finance Management Courses in University
}

\author{
Xuan Chen, Yi-Jun Luo \\ School of Economics and Management, Shanghai Ocean University, Shanghai, China
}

\begin{abstract}
Based on the foregone teaching practice, the current study analyzes the shortage of illumination, interesting and simplification in introduction of new knowledge when the teachers give lectures on the courses of finance management in University. Then, we expatiate the implementation strategy, including innovating tradition mode, handling visual aid, setting cliffhang, improving the occasion and so on.
\end{abstract}

Keywords - finance management, teaching, introduction

\section{大学财务管理教学课堂导入的探讨}

\author{
陈璇 罗奕君 \\ 上海海洋大学经济管理学院, 上海, 中国
}

摘 要 本文结合当前财务管理教学实践, 分析了当前财务管理课程教学在导入上存在的缺乏启发性、趣味性和精简性等问题, 并从创新传统导入方式、运用直观教具、设置悬疑、因势利导几个方面阐述了财务管理教学课堂导入的实施策略。

关键词 财务管理, 教学, 导入

\section{1. 引言}

上课伊始, 教师如果能借用某种形式, 在课堂上形成一 种具有感染力、催人向上的教学情境, 以此刺激学生处于 一种兴奋的精神状态, 使学生更加积极主动地参与课堂教 学, 更好地接受新知识, 提高财务管理教学学习效率。因 此, 财务管理教学教师都应重视课堂导入 [1]。

所谓导入, 又称其为 “导课” 或者是 “开场白”, 是指 在讲授新课或开始展开教学活动时, 教师运用各种教学手 段唤起学生注意力, 激发学生学习兴趣, 引导学生进入预 设的程序和轨道之中的教学技能。一个好的导入能引导学 生进入情境、提高学习兴趣、唤起学生求知欲[2]。

当然, 导入的好坏并没有一个固定的评价标准, 有的 导入, 设计精良, 构思巧妙, 可在实际的课堂教学中却没 有起到什么作用, 甚至与教师预设的内容大相庭径, 我们 只能很遗憾地说, 这个导入并不适合那堂课。相反的, 有 的导入能巧妙地配合课堂教学的各个环节, 优化教学设计, 那我们就可以说这是一个好的导入, 哪怕它的设计只是很 简短的几句话。

\section{2. 财务教学课堂导入教学提出的内涵和意义}

所谓导入, 又称其为 “导课” 或者是 “开场白”, 是指 在讲授新课或开始展开教学活动时, 教师运用各种教学手 段唤起学生注意力, 激发学生学习兴趣, 引导学生进入预 设的程序和轨道之中的教学技能。简单的说, 导入就是利 用课堂的几分钟时间对新课的一种介绍方式，它有承上启 下、调动兴趣、活跃气氛的功能, 是教师有针对性地引导 学生进入预定的教学程序的一种教学技能。

于渏老师认为 [1]: “在课堂教学中, 要培养激发学生的 兴趣, 首先应抓住导入课文的环节, 一开课就要把学生牢 牢地吸引住。课的开始好比是提琴家上弦, 歌唱家定调, 第一个音定准了, 就为演奏和歌唱奠定了基础。上课也是 如此, 第一锤就应敲在学生的心灵上, 像磁石一样把学生 牢牢地吸引住。”可以毫不客气的说, 一个好的导入就是一 把教师精心锤炼出来的金钥匙, 它有着独特的光芒, 散发 着神秘的魅力, 能够带领学生在知识的殿堂里䢩游。

曾做过一个实验: 将本校六年级 8 各班分为两组, 一 组的课堂教学使用导入设计, 另一组的教学不用导入设计。 一个月后调查结果显示: 使用导入的班级无论在态度上还 
是在学习效率和学习效果上都明显优于另一组。实践证明, 富有启发性的导入能够快速吸引学生的注意力, 激发学生 的学习兴趣, 引导学生快速进入积极的学习状态。

正如所前人形容的一样: “好的导语像磁铁, 一下子把 学生的注意力聚拢起来, 好的导语又是思想的电光石火, 能给学生以启迪, 催人奋进。”

良好的开端是成功的一半, 而导入就是为引入新课所 设计的第一个教学步骤, 它连接新旧课文的内容, 启发思 维, 调动情绪, 营造氛围, 是课堂教学的重要组成部分, 是教学成败至关重要的一环。

一个好的导入能引导学生进入情境、提高学习兴趣、 唤起学生求知欲、从而渗透课文主题的妙用。当然, 导入 的好坏并没有一个固定的评价标准, 好如说有的导入, 设 计精良, 构思巧妙, 可在实际的课堂教学中却没有起到什 么作用, 甚至与教师预设的内容大相庭径, 我们只能很遗 憾地说, 这个导入并不适合那堂课。相反的, 有的导入能 巧妙的配合课堂教学的各个环节, 优化教学设计, 那我们 就可以说这是一个好的导入, 哪怕它的设计只是很简短的 几句话。

\section{3. 当前财务管理课程教学在导入上存在的问题}

（1）教师的导入缺乏启发性

良好的导入不但能使学生对知识产生浓厚的兴趣, 而 且能启发学生积极开动脑筋思考问题, 我国古代著名教育 家孔子是世界上最早主张启发性教学的人, 他认为在教学 中应该 “不愤不启, 不悱不发, 举一隅不以三隅反, 则不 复”。这说明启发式教学能调动学生求知的主动性和积极 性, 同时还能找到求知的途径和方法。《学记》也说 “君子 之教, 喻也。” 这里说的 “喻” 其实就是启发诱导的意思, 由此想到彼、由因想到果, 由表想到里、由个别想到一般, 收到启发思维的教学效果。

在现实的财务管理教学课堂教学中, 有些财务管理教 学教师并没有真正领悟到何谓 “启发式” 教学, 他们简单 地认为在教学中设计一些有趣的问题让学生回答, 或者组 织一些丰富多彩的课堂讨论形式, 让学生自由讨论, 就是 激发学生的学习兴趣, 引起学生的思考。有的教师已经意 识到了启发式教学的重要性, 但是缺乏精心的设计, 仅用 一些辅助性手段, 提出的问题也缺乏综合性、评价性这种 高水准的认识层面, 尤其缺乏对创造性思维的开发方面的 问题, 对待问题的解读只是蜻蜓点水, 草草而过, 一味地 牵着学生的鼻子往下走。如此的教学方式, 长此以往, 不 仅学生学习财务管理教学的热情会逐渐消退, 还会使学生 养成不良的学习态度和思维惰性。

\section{（2）教师的导入缺乏趣味性}

在传统的财务管理教学中, 教师备课只备教材, 授课 过程也是按照教案的设计进行。事实上, 教学按照设定好 的教案走, 是有利于知识点的讲授, 避免重难点遗漏的, 只不过这样的课堂教学往往让人觉得死板僵化, 学生提不 起学习的兴趣。在教师预设的过程当中, 只有互动的形式 而没有互动的实质, 课堂的主动权基本上归教师所有, 学 生处于被领导地位, 师生之间缺乏平等的对话与交流。有 的教师甚至不使用导入直接进行教学, 他们的理由是学生 都知道要上哪部分内容, 根本没有导入的必要。这就不仅 是单纯的缺乏趣味性了, 而是教师的导入意识淡薄, 对于 导入这样一个具有重要作用的教学环节, 又岂是教师仅凭 好恶喜欢用就用, 不喜欢用就可以不用的呢?

（3）教师的导入缺乏精简性

导入语要求做到巧妙而迅速地缩短学生与教师、学生 与教材之间的距离, 将学生的兴趣吸引到课堂上来。因此 导入不宜太多, 导入的时间也不宜过长, 一般不超过五分 钟。然而, 在现实的教学中, 有的教师并不能很好的掌握 这个 “时间度”。在我们沉醉于多媒体带来便利的同时却忽 略了课堂教学的主次, 忽视文本内容。甚至有的教师, 将 三分之二的时间用于播放视频, 让学生观赏, 仅在最后几 分钟讲解课文内容, 草草结束教学, 这样的导入不能够称 为导入。

\section{4. 当前财务管理课程教学在导入上存在的问题}

优秀的财务管理教学课堂导入不是一成不变的, 它没 有固定的格式, 不同的课型可以有不同的导入方式, 同一 课型也可以有不同的导入方式, 设计的关键在于教师对教 材的理解和对学生的研究, 根据不同的教学内容、不同的 文体、不同的教学情境以及学生的心理特征来选用导入的 方式。在这里, 笔者主要从以下四个方面进行说明。

\section{（1）另辟蹊径，开门见山}

开门见山、直接导入是最传统的一种导入方法, 它是 在开始教学时, 教师单刀直入, 直奔主题、阐明学习的目 的和要求, 使学生迅速进入到学习情境中的一种导入方法。 导入时教师要用简洁明快的叙述和提问, 直接把新旧知识 的冲突展现在学生面前, 提纲絜领地讲清楚重难点。

直接导入, 不拐弯抹角, 具有针对性、目的性、直接 性和简洁性的特点, 能使学生迅速进入主题, 节省教学时 间。但是这种导入方法如果运用的不好, 容易平铺直叙流 于平淡, 缺乏强烈的感染力, 短时间内难以让学生集中注 意力, 造成 “导而不入” 的情况。因此, 创造性地使用直 接导入, 另辟蹊径, 开门见山是第一点需要我们注意的。 
在财务管理课程教学中, 教师可以将主要财务理论分 成多个专题, 每个专题又可以从财务实践开始, 引入理论 问题, 然后对相关理论作深入讲解, 最后再引入现实现象 或案例进行佐证[3]。例如, 在讲授 “风险报酬” 时, 不妨 就以 “舍不得孩子套不住狼”、“不入虎穴, 焉得虎子” 等 俗语作为导入点, 引出 “风险补偿” 与 “风险水平” 的关 系, 然后围绕这其中的关系系统阐述风险报酬思想及其经 典理论。

（2）运用直观教具，寓教于乐

随着教学设施的现代化, 教学导入的路径就显得更加 宽阔, 许多直观手段的引进课堂, 使得课堂教学发生着巨 大的变化。实验心理学家们做过关于人类获取信息来源的 实验。实验证实: 人类获取的信息反馈 $90 \%$ 以上来自视觉 和听觉。由此可见, 课堂上直观教具的运用对于开启学生 被动参与学习活动的封闭状态, 唤醒沉睡已久的自我深层 感受, 提高学生接受知识后的迁移能力有着举足轻重的作 用。

多媒体课件集文字、图像、动画于一体, 为学生在课 堂上的想象和思考提供了渠道, 而且这个渠道的刺激还不 是简单的唯一刺激, 而是多种感观的综合刺激。多媒体作 为一种重要的直观教具, 集声形色于一体, 化抽象为形象, 为财务管理教学创设了丰富多彩、逼真形象的语言环境, 更为学生把感性和理性结合起来创造了有利条件。比如, 本人在财务管理课程教学中, 在讲授股票定价之前, 就先 应用 flash 将股票价格影响因素、股票投资收益等该部分知 识点全部包括在其中, 系统地向学生直观展示了该部分结 构, 增强了学生对知识整体性的把握和学习兴趣。

（3）投石问路, 巧设悬疑

“疑问” 其实是一种认知的张力, 具有很强的奋发作 用, 教师在讲授新课之前, 若能抓住关键, 有的放矢的巧 设悬疑, 往往可以使人萌发心理期待, 产生扣人心弦的诱 惑力, 激起欲知其详的渴望。教师根据教材内容巧设悬念, 能激发学生的兴趣, 调动学习积极性, 给教学过程增添活 力, 取得良好的教学效果。

特别是, 教师在课程教学中要充分利用课前的教学互 动[4]。课前, 通过教室课堂告知学生下次课的教学内容, 提示分析所需的背景知识与资料, 布置思考讨论题, 引起 学生兴趣。兴趣是创造一个欢乐和光明的教学环境的主要 途径之一。导入的问题设置要在充分考虑教材的基础上, 具有强烈的趣味性, 促使学生产生强烈的探究欲望, 产生 欲罢不能、乐于追究的动力, 诱导学生由疑而思, 启迪感 悟。
（4）因势利导，因材施教

教学过程是一种开放的活动过程, 在新课程教学理念 指导下, 学生日益成为学习的主体, 这使得教学过程中的 不确定因素愈加增多。如何因势利导, 在课堂伊始就化腐 朽为神奇, 是教师教学机智的一种表现。

教学课堂中独特的教学资源首先来源于教师处理教材 的主观性, 每一位教师对材料都有自己独特的理解, 还能 根据本班学生的实际情况在教学过程中进行适当的处理, 对教材的内容进行合理的删减和增补, 从而让导入更加接 近学情, 最大限度地激发学生的发展需求。

特别是在 MBA 教学中, 教师可以在授课之前对学生 的年龄、从业性质、职业位阶、社会阅历等作全面的调查 摸底, 并深入细致地分析其具体状况和特点, 推测出授课

对象目前已拥有的与本课程相关的前期知识基础、所 关注的课程知识的侧重点以及期望解决的现实问题等 [4]。 在此基础上, 有选择地对教学内容作出调整, 有针对性地 导入知识点, 以便尽可能地满足学生的心理预期和诉求, 提升学生学习积极性。

\section{5. 结论}

注重新课导人的艺术是力抓课堂教学流程、优化课堂 教学结构、提高 45 分钟效率的重要方面和基本保证。“一 个真正懂得利用时间的教师不会吝惜导入的时间, 一个不 愿在导入上花费时间的教师也绝对算不上一个善于利用时 间的教师。” 因此, 作为一名专业的大学财务管理课教师, 应该根据财务管理教学的规律, 全方位、多层次地调动起 学生学习财务管理知识的内动力, 设计出新颖独特的课堂 导入形式, 让整个课堂教得生动、学得主动, 使学生真正成 为课堂的主体, 为实现知识能力与素养品德方面的同步发 展奠定坚实的基础, 在未来的课堂上散发夺目的光芒。

\section{参考文献(References)}

[1] Y. Yu. Education analects on finance management teaching. Beijing: People's Education Press, 1996. (in Chinese)

[2] R. S. Wu. "The issue and ponder on new knowledge introduction of finance management courses in University". Teaching Monthly (University Edition), no.11, pp. 43-44, 2007. (in Chinese)

[3] K. Chao. "Reflections on the case teaching of undergraduate financial". Theory and Practice of Education, vol. 34, no. 6, pp. 46-47, 2014. (in Chinese)

[4] J. P. Dai. "The reformation and baffle in multiple dimension case teaching". Finance and Accounting Monthly, no.11, pp. 120-122, 2013. (in Chinese)

[5] M. J. Li. "How to get good teaching effects in MBA courses?- finance management as a sample". Academic Degrees \& Graduate Education, no. 11, pp. 13-16, 2012. (in Chinese) 